\title{
Dorsomedial thalamic lesions and amphetamine: Acquisition and retention of a visual pattern discrimination escape task
}

\author{
KARL L. WUENSCH, BELINDA BROOME, LARRY W. MEANS \\ and EVANS C. HARRIS, JR. \\ East Carolina University, Greenville, North Carolina 27834
}

\begin{abstract}
Two experiments were conducted to examine the performance of DMT-lesioned rats in a water-filled maze, a task on which it was expected that the freezing often manifested by such animals in aversive situations would be eliminated as a possible explanation of deficit. The lesioned animals showed both acquisition and retention deficits, but freezinglike behaviors were not eliminated as a possible interpretation. A third experiment effectively used amphetamine dosage to break up freezing-like responses, but no accompanying reduction in deficit was demonstrated.
\end{abstract}

Damage to the dorsal medial thalamus (DMT) has been shown to produce performance deficits on several relatively complex appetitive tasks. Rats with DMT lesions have shown deficits on acquisition of a brightness and tactile discrimination (Tigner, 1974) and of a go, no-go, tone-light discrimination task (Means, Harrington, \& Miller, 1975), on retention of a two-bar alternation task (Gross, Chorover, \& Cohen, 1965), and on both acquisition and retention of a single-alternation go, no-go task (Means, Hunt, Whiteside, \& Bates, 1973) and of a visual-tactile discrimination task (Means, Huntley, Anderson, \& Harrell, 1973; Waring \& Means, 1976). Deficits have not been found in a relatively simple appetitive tasks such as approaches to food or water (Vanderwolf, 1967) and runway acquisition (Means, Harrell, Mayo, \& Alexander, 1974).

Acquisition and retention deficits on both oneand two-way active avoidance tasks have also been demonstrated in rats with medial thalamic damage (Delacour, 1971; Olton \& Isaacson, 1967; Vanderwolf, 1962, 1963, 1967). It has been difficult to interpret such poor performance in terms of learning or memory deficits. The avoidance deficit is not likely due to deficient fear conditioning, several studies having reported normal classical fear conditioning in rats with DMT lesions (Thompson, 1963; Vanderwolf, 1963, 1969).

DMT-lesioned animals usually show normal escape

Experiments 1 and 2 of this paper are based on an MA thesis submitted by Belinda Broome to East Carolina University. The authors wish to thank Gary M. King and Henry Hooks for their assistance. Requests for reprints should be sent to Karl L. Wuensch, Department of Psychology, Miami University, Oxford, Ohio 45056. behavior but fail to avoid onset of shock (Vanderwolf, 1962). Vanderwolf (1971) has proposed that the deficit shown by DMT-lesioned animals in avoidance tasks is accounted for by impaired initiation of voluntary movement. Cats with lesions of the dorsomedial nucleus of the thalamus make significantly more crouching or freezing responses and fewer upward flight movements in classical fear conditioning than do normal animals (Roberts \& Carey, 1963). Delacour (1971) has also observed increased frequency of freezing among medial thalamic-lesioned rats in aversive situations.

The purpose of the present study was to assess the performance of DMT-lesioned rats in an aversive situation with conditions arranged such that any deficit shown could not be reasonably interpreted in terms of freezing or failure to initiate voluntary movement.

\section{GENERAL METHOD}

\begin{abstract}
Subjects
One hundred and seven male Long-Evans rats, approximately 90 days of age at the beginning of their respective experiments, were used as subjects. All rats were housed individually and maintained on a 14-h-light, 10-h-dark cycle, with food and water continuously available.
\end{abstract}

\footnotetext{
Apparatus

Behavioral testing in all three experiments was conducted in a two-choice, water-filled, discrimination maze illustrated in Figure 1. The maze consisted of a startbox, choice point, and two goalboxes with elevated platforms. Two black guillotine doors, with interchangeable stimulus panels, separated the choice point from the goalboxes. One stimulus panel had 13-mm-wide black and gray horizontal stripes, and the other had 13-mm-wide black and gray vertical stripes. The maze was filled with water to just below the height of the platforms in the goalboxes. The
} 


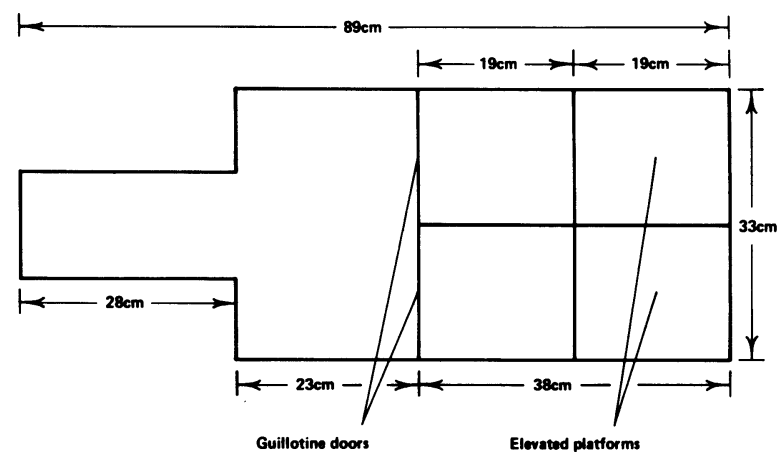

Figure 1. Diagram of two-choice, water-filled discrimination maze.

water was kept within $2^{\circ} \mathrm{C}$ of room temperature, which was approximately $25^{\circ} \mathrm{C}$. The maze was slightly modified for Experiments 2 and 3 by attaching a narrow black panel between the guillotine doors, extending $0.5 \mathrm{~cm}$ into the choice point.

\section{Surgical and Histological Procedures}

Surgery was performed using Nembutal $(45 \mathrm{mg} / \mathrm{kg})$ for anesthesia and $0.20 \mathrm{ml}$ Bicillin as a prophylactic. Bilateral lesions of the DMT were produced by passing $2.0 \mathrm{~mA}$ anodal current for $15 \mathrm{sec}$ through stainless steel electrodes, insulated with Epoxylite except for the tip. Electrodes were stereotaxically placed $1.2 \mathrm{~mm}$ posterior to bregma, $1.0 \mathrm{~mm}$ lateral to the midline, and $6.2 \mathrm{~mm}$ ventral to the top surface of the skull. The top of the incisor bar was elevated $5.0 \mathrm{~mm}$ above interaural zero. Bilateral sham lesions were created by lowering the electrodes $5.0 \mathrm{~mm}$ into the brain at the same anterior-posterior and lateral coordinates, but passing no current.

Rats sustaining DMT lesions were examined neurohistologically. The animals were sacrificed and intracardially perfused with saline and then Formalin. The brains were then removed, sectioned at $50 \mu$, and photographed with Kodak high-contrast copy film. The negatives were projected onto plates from Pellegrino and Cushman's (1967) atlas, and a square counting procedure was used to determine total lesion size and amount of bilateral damage to the various thalamic and extra-thalamic structures.

The lesions were generally centered on the dorsomedial nucleus of the thalamus, and all lesions included extensive bilateral damage to the stria medullaris and periventricular nucleus as well. Most experimental animals also sustained some degree of bilateral damage to the habenula, anterodorsal nucleus, paratenial nucleus, parafascicular nucleus, and anteroventral nucleus. Four subjects were determined to have sustained misplaced lesions, and accordingly their data were discarded. Figure 2 shows a typical lesion and Figure 3 shows the largest and the smallest lesions.

\section{EXPERIMENT 1: ACQUISITION}

Experiment 1 was designed to determine whether DMT-lesioned rats would show a deficit relative to sham-operated controls on acquisition of the discrimination task in a water-filled maze. It was assumed that using the water-filled maze would eliminate freezing.
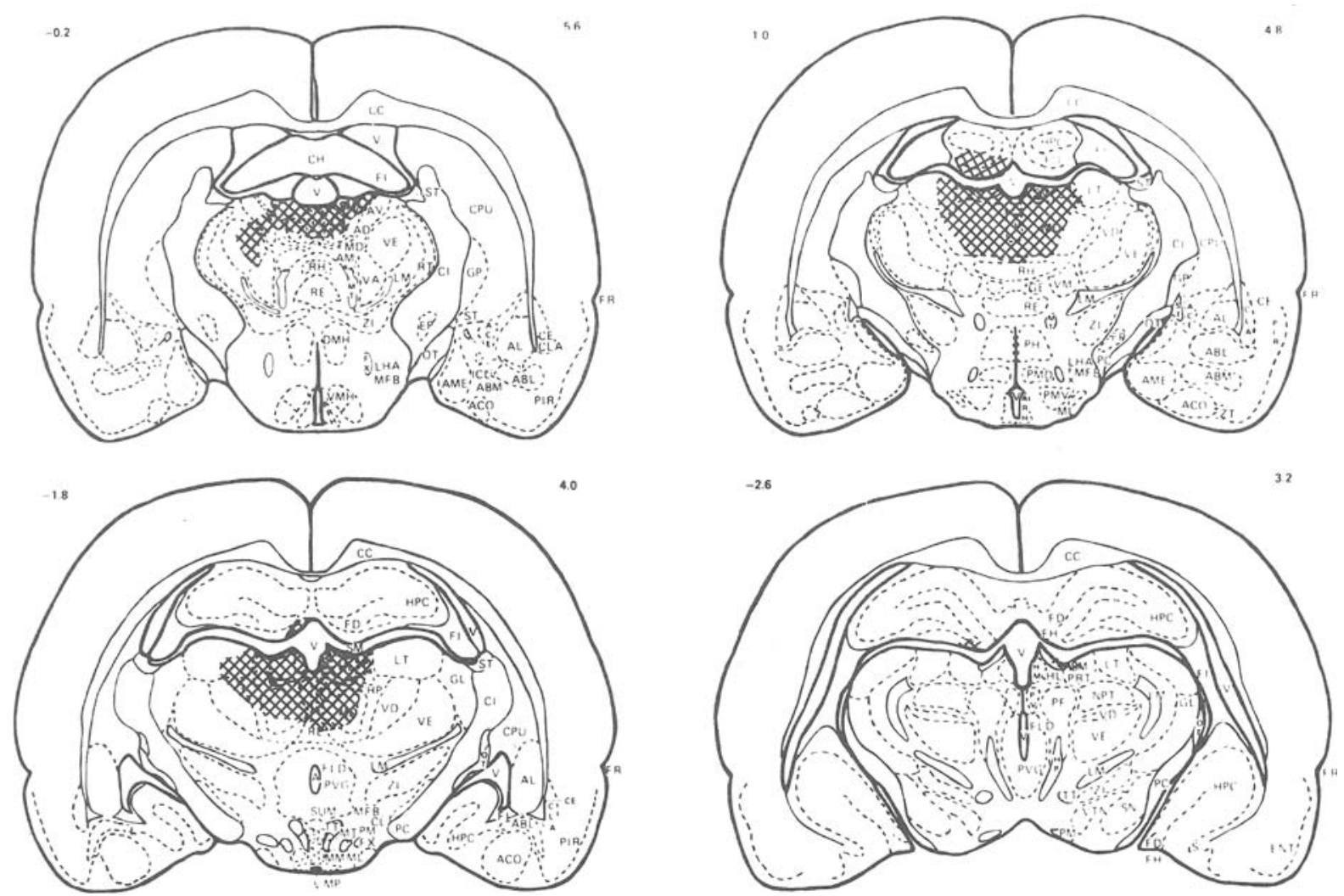

Figure 2. Reconstruction of a typical lesion. 

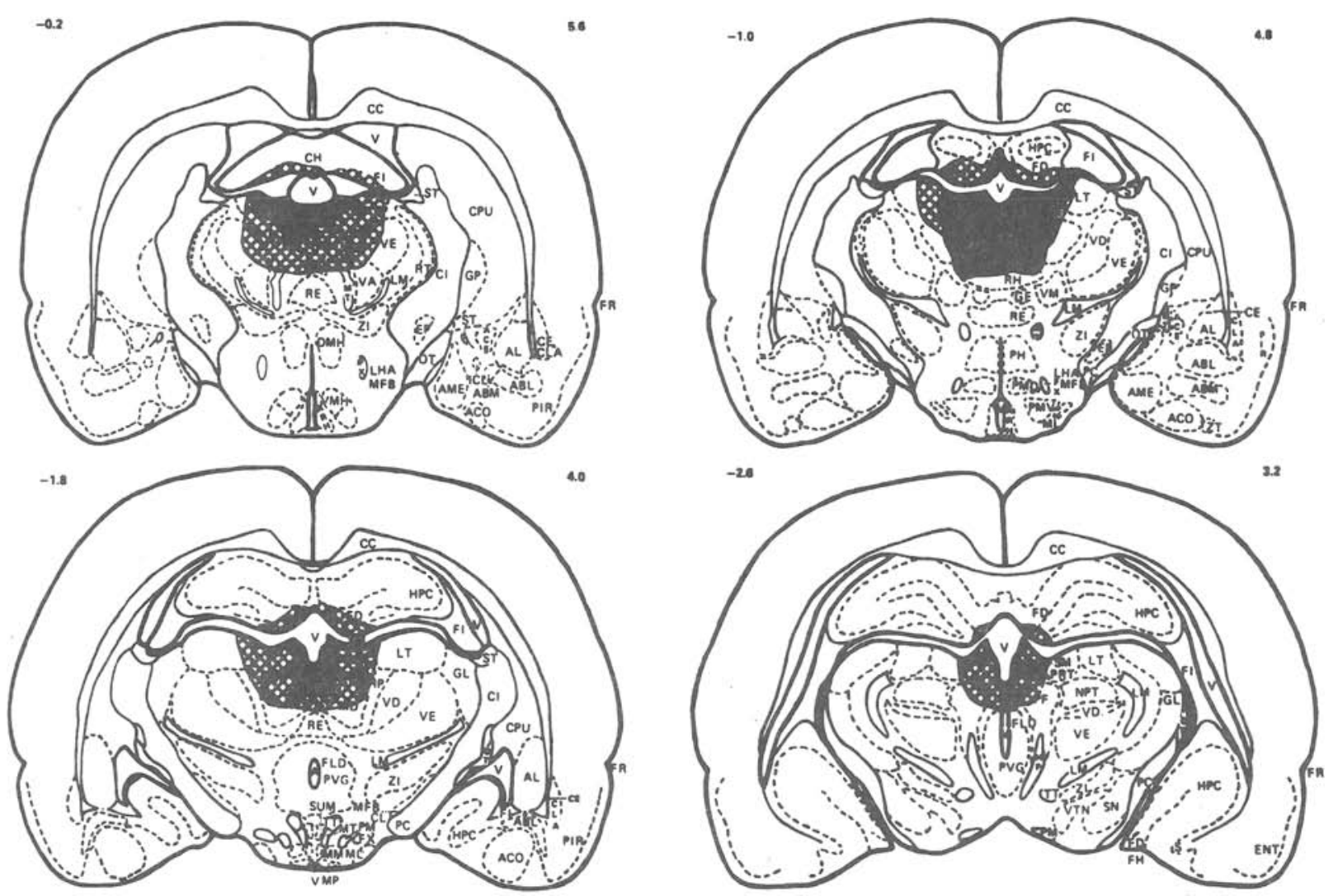

Figure 3. Reconstruction of largest (cross-hatch) and smallest (solid) lesions.

\section{Method}

Twelve rats with DMT lesions and 12 sham-operated controls were subjects in the acquisition experiment. Eighteen days after surgery, all rats were handled in groups of six for 10-15 min on 7 consecutive days. Subjects were then given 2 days of maze adaptation in the water-filled maze using the guillotine doors with stimulus panels removed. Ten trials were given each day, using a forced-choice procedure. A choice was defined as a rat's nose coming within 1.0 to $2.0 \mathrm{~cm}$ of one of the guillotine doors. Odd-numbered trials were free choice, and even-numbered trials were forced choice to the side opposite that chosen on the preceding trial. When the free or correct forced choice was made, the guillotine door was raised, allowing the rat to enter the goalbox and climb up onto the dry platform. Each subject spent the 5-10 min between trials in his home cage.

Discrimination training commenced on the day following completion of maze adaptation. Each subject was given 10 trials per day with an intertrial interval of 5-10 min for 200 trials or until the subject reached the criterion of at least $90 \%$ correct choices on each of 3 consecutive days. Half of the subjects were trained to horizontal stripes and half to vertical. The stimulus panels were rotated from door to door between trials according to a Gellerman sequence. When a subject made an incorrect choice, he was allowed to swim until he made the correct choice or until $\mathbf{3} \mathrm{min}$ had elapsed. If a subject failed to made a correct choice within $3 \mathrm{~min}$ on three consecutive trials, his session was terminated for that day. Subjects who had sessions terminated on 2 consecutive days were dropped from the study.

\section{Results}

Among the DMT-lesioned animals, two were dropped due to misplaced lesions and two due to session termination. One sham animal was dropped due to session termination. Table 1 shows the mean numbers of sessions and errors to criterion. Alpha was set and held at .05 for all statistical tests in this and the following two experiments. Lesioned animals required a greater number of sessions to reach criterion $(t=2.76)$ and made more errors $(t=2.81)$ than did sham-operated animals.

\section{EXPERIMENT 2: RETENTION}

Experiment 2 was designed to determine whether DMT-lesioned rats would show a deficit relative to sham-operated controls on reacquisition of the preoperatively acquired discrimination task in the waterfilled maze.

Table 1

Mean Number of Sessions and Errors to Criterion for Experiment 1: Acquisition

\begin{tabular}{ccc}
\hline Group & Sessions & Errors \\
\hline DMT & 15.5 & 56.2 \\
Sham & 6.8 & 22.0 \\
\hline
\end{tabular}




\section{Method}

Twenty-four rats were handled and maze adapted as in Experiment 1. Discrimination training proceded as in Experiment 1, with each rat continuing training until he had reached the criterion of at least $90 \%$ correct choices on each of 3 consecutive days. Surgery was performed on each rat the day after he reached criterion. Twelve subjects received DMT lesions, and 12 received sham surgery. Following an 18 -day recovery period, each rat was again given discrimination training for 150 trials or until he had reached criterion. Choices and latencies from startbox to correct choice were recorded. If a subject froze, that is, did not enter the goalbox within 10 min after making a correct choice, he was removed from the maze. Any rat that froze on three consecutive trials had his session terminated for the day, and 2 consecutive days of session termination resulted in the subject's being dropped from the study.

\section{Results}

Within the DMT-lesioned group, two subjects were dropped preoperatively for failure to reach criterion, one preoperatively for swimming underwater, one postoperatively for failure to respond in the maze, and two because of misplaced lesions. One subject in the sham group was dropped preoperatively due to failure to reach criterion.

Table 2 shows a summary of the data for Experiment 2. Data were analyzed to determine the effects of type of surgery (DMT vs. sham) and time of testing (preoperative vs. postoperative). Such analyses on sessions, errors, and latency data yielded significant $\mathrm{F}$ ratios $(\mathrm{df}=1 / 15$ and $\mathrm{p}<.05$ in each case) for type of surgery $(F s=14.07,14.18$, and 16.57, respectively), time of testing (Fs $=7.60,9.19$, and 5.65, respectively), and their interaction (Fs = $33.12,23.87$, and 8.78 , respectively). Tukey's test was used to make specific comparisons between means. While lesion and sham groups did not differ significantly on any measure preoperatively, postoperatively the lesioned animals required a greater number of sessions to reach criterion on reacquisition, made more errors, and had longer latencies than did sham-operated animals. Both sessions and error data indicated that the shams showed savings (better postoperative reacquisition performance than original preoperative acquisition performance), but that the lesioned animals' postoperative performance was poorer than it had been preoperatively. Postoperatively, the DMT group showed longer latencies than it had before surgery.

Table 2

Pre- and Postoperative Means for Sessions, Errors to Criterion, and Latency (in Seconds) for Last Two Preoperative and First Two Postoperative Sessions

\begin{tabular}{lcccccccc} 
& \multicolumn{2}{c}{ Sessions } & & \multicolumn{2}{c}{ Errors } & & \multicolumn{2}{c}{ Latency } \\
\cline { 2 - 3 } Group & Preop & Postop & & Preop & Postop & & Preop & Postop \\
\hline DMT & 7.8 & 12.7 & & 33.3 & 47.2 & & 2.8 & 5.6 \\
Sham & 7.7 & 1.0 & & 28.1 & 2.5 & & 2.6 & 2.7 \\
\hline
\end{tabular}

Table 3

Mean Number of Sessions and Errors to Criterion for Experiment 3: Amphetamine

\begin{tabular}{lrrrrrrr}
\hline & \multicolumn{3}{c}{ Sessions } & & \multicolumn{3}{c}{ Errors } \\
\cline { 2 - 4 } \cline { 6 - 8 } Group & Saline & $1.0^{*}$ & 2.5 & & Saline & 1.0 & 2.5 \\
\hline DMT & 15.0 & 20.0 & 16.9 & & 65.3 & 88.8 & 84.0 \\
Sham & 7.8 & 6.9 & 8.9 & & 33.1 & 26.6 & 33.6 \\
\hline
\end{tabular}

*Dosage of amphetamine in $\mathrm{mg} / \mathrm{kg}$.

\section{EXPERIMENT 3: AMPHETAMINE}

Use of the water-filled maze did eliminate freezing in the usual sense of total bodily immobility; to freeze in such fashion would have resulted in drowning. Lesioned animals did show two behavioral patterns which may be described as active freezing in that there was some bodily motion, yet no locomotion. Such freezing in the startbox was characterized by the animal's slowly treading water while remaining in one place. After having made a correct choice and the guillotine door to the goalbox having been raised, some animals clung to the tracks within which the door rode. Such clinging was also categorized as active freezing. Experiment 3 was designed to determine whether the pattern of active freezing in the water maze could be broken up by administration of a stimulant to the animals.

\section{Method}

Thirty-five rats with DMT lesions and 24 shams were used as subjects. Handling and maze adaptation proceded as in Experiment 1. The subjects were assigned to three different drug groups. Each subject received an intraperitoneal injection of either physiological saline or d-amphetamine 20 min prior to the start of behavioral testing on each day of discrimination training. Dosages of amphetamine used were 1.0 and $2.5 \mathrm{mg} / \mathrm{kg}$. Eight shams were assigned to each level of drug dosage. Among the DMT-lesioned animals, 14 were assigned to the saline group, 8 to the $1.0-\mathrm{mg} / \mathrm{kg}$ group, and 13 to the $2.5-\mathrm{mg} / \mathrm{kg}$ group. The only deviation in procedure from that used for discrimination training in Experiment 1 was that a subject's daily session was terminated if he froze (did not enter goalbox within 3 min regardless of choice behavior) on any 3 of that day's 10 trials.

\section{Results}

Eleven of the DMT-lesioned animals were dropped from the study due to session termination resulting from persistent freezing. Seven of these were in the saline group, one in the $1.0-\mathrm{mg} / \mathrm{kg}$ group, and three in the $2.5-\mathrm{mg} / \mathrm{kg}$ group. No shams were dropped. Among the DMT-lesioned animals, the proportions of subjects dropped were .50 for the saline group and .19 for the amphetamine groups. These proportions were determined to be significantly different from one another $(z=1.96)$, indicating that the amphetamine administration did reduce freezing.

Table 3 shows the mean numbers of sessions and 
errors to criterion. Analyses of variance indicated that compared to sham-operated controls, the DMTlesioned animals took significantly more sessions to reach criterion $(F=43.56, \mathrm{df}=1 / 42)$ and made more errors $(F=50.15$, df $=1 / 42)$. Neither drug nor Drug by Surgery yielded significant $F$ ratios with sessions to criterion data ( $F s=0.90$ and 1.26, respectively, $\mathrm{df}=2 / 42$ ) or with errors data (Fs = 1.31 and 0.81 , respectively, $\mathrm{df}=2 / 42$ ).

\section{DISCUSSION}

Results of the three experiments clearly reveal that DMT-lesioned animals show deficits on both acquisition and retention of a visual pattern discrimination in a water-filled maze. Such results are consistent with those of other studies cited in the introduction, indicating that DMT-lesioned animals show acquisition and retention deficits on relatively complex appetitive tasks and on active avoidance tasks.

It had been hoped that the use of a water-filled maze would eliminate freezing from the interpretation of any deficits shown in Experiments 1 and 2. Increased postoperative latencies of the DMT-lesioned animals in Experiment 2 and observations made by the experimenters during data collection suggested that the usual passive freezing shown by such animals in aversive situations has a more active counterpart in the water maze. Such active freezing, bodily motion without locomotion, was observed to occur not only in the startbox, but also at the goalbox entrance after the subject had already chosen the correct door. Freezing at the correct goalbox entrance was not reflected in the latency data, but could have accounted for at least part of the deficit by lengthening the delay of reinforcement between correct choice and escape from the water.

If one is willing to consider treading water and clinging to parts of the apparatus as reflexive behaviors, then the prolonged maintenance of such behaviors in DMT-lesioned animals may be interpreted as being due to a lesion-produced reluctance to initiate voluntary movement. Viewed from such perspective, the behavioral patterns described as active freezing in the water maze are analogous to the more passive freezing shown by DMT-lesioned animals in other aversive situations. An alternative, but not necesarily incompatible, interpretation could be made in terms of response perseveration, but in any case it appears that the freeze-producing effect of DMT lesions is something other than just enhancement of immobility.

Administration of d-amphetamine in Experiment 3 did effectively reduce the amount of freezing among the DMT-lesioned animals, as evidenced by the amphetamine groups' lower proportion of such animals dropped due to freezing. The reduction of freezing was not, however, accompanied by any reduction in deficit. Although these results should not be interpreted as totally negating the role of freezing in DMT-lesioned animals' performance deficit under aversive circumstances, they do indicate that other factors more clearly associative in nature must be involved. Further research is needed to reveal whether the deficit stems more specifically from disruptions of stimulus registration, attention to relevant cues, consolidation, or some other process.

It should be noted that recent research indicates that administration of chlorpromazine does reduce, but not eliminate, the deficit shown by DMT-lesioned rats on a one-way active avoidance task (Wuensch \& Means, 1976). Although hyperemotionality has been eliminated as an explanation of DMT-lesioned rats' poor performance on an appetitively motivated visual-tactile discrimination task (Means, Huntley, Anderson, \& Harrell, 1973; Waring \& Means, 1976), the chlorpromazine-induced reduction of deficit on the shock avoidance task suggests that some deviant pattern of emotionality may contribute to the deficit, at least when performance is motivated by aversive stimuli. If such is the case, the presumably facilitative effects of amphetamine-induced reduction of freezing may have been offset by an accompanying increase in emotionality. Further research investigating the effects of tranquilizing agents upon both freezing and performance under aversive circumstances is needed to clarify this possible interpretation.

\section{REFERENCES}

Delacour, J. Effects of medial thalamic lesions in the rat: A review and an interpretatiion. Neuropsychologia, 1971, 9, 157-174.

Gross, C. G., Chorover, S. L., \& Cohen, S. M. Caudate, cortical, hippocampal, and dorsal thalamic lesions in rats: Alternation and Hebb-Williams maze performance. Neuropsychologia, 1965, 3, 53-68.

Means, L. W., Harrell, T. H., Mayo, E. S., \& Alexander, G. B. Effects of dorsomedial thalamic lesions on spontaneous alternation, maze activity and runway performance in the rat. Physiology \& Behavior, 1974, 12, 973-979.

Means, L. W., Harrington, J. H., \& Miller, G. T. The effect of medial thalamic lesions on acquisition of a go, no-go, tonelight discrimination task. Bulletin of the Psychonomic Society, 1975, 5, 495-497.

Means, L. W., Hunt, M. W., Whiteside, R. R., \& Bates, T. W. Deficient acquisition and retention of a single-alternation go, no-go in rats with medial thalamic lesions. Physiological Psychology, 1973, 1, 287-291.

Means, L. W., Huntley, D. H., Anderson, H. P., \& Harrell, T. H. Deficient acquisition and retention of a visual-tactile discrimination task in rats with medial thalamic lesions. Behavioral Biology, 1973, 9, 435-450.

Outon, D. S., \& IsAACson, R. L. Effects of lateral and dorsomedial thalamic lesions on retention of active avoidance tasks. Journal of Comparative and Physiological Psychology, 1967, 64, 256-261.

Pellegrino, L. J., \& Cushman, A. J. A stereotaxic atlas of the rat brain. New York: Appleton-Century-Crofts, 1967. 
Roberts, W. W., \& CAREY, R. J. Effect of dorsomedial thalamic lesions on fear in cats. Journal of Comparative and Physiological Psychology, 1963, 56, 950-958.

Thомpson, R. Thalamic structures critical for retention of an avoidance conditioned response in rats. Journal of Comparative and Physiological Psychology, 1963, 56, 261-267.

TIGNER, J. C. The effects of dorsomedial thalamic lesions on learning, reversal, and alternation behavior in the rat. Physiology \& Behavior, 1974, 12, 13-17.

VANDERWOLF, C. H. Medial thalamic functions in voluntary behavior. Canadian Journal of Psychology, 1962, 16, 318-330.

VANDERWOLF, C. H. The effect of medial thalamic lesions on previously established fear-motivated behavior. Canadian Journal of Psychology, 1963, 17, 183-187.

VANDERWOLF, C. H. Effects of experimental diencephalic damage on food hoarding and shock avoidance behavior in the rat. Physiology \& Behavior, 1967, 2, 399-402.
VANDERWOLF, C. H. Effects of medial thalamic damage on initiation of movement and learning. Psychonomic Science, 1969, 17, 23-25.

VANDERWOLF, C. H. Limbic-diencephalic mechanisms of voluntary movement. Psychological Review, 1971, 78, 83-113.

Waring, A. E., \& Means, L. W. The effect of medial thalamic lesions on emotionality, activity, and discrimination learning in the rat. Physiology \& Behavior, 1976, 17, 181-186.

Wuensch, K. L., \& Means, L. W. Chloropromazine reduces avoidance performance deficit in rats with dorsomedial thalamic lesions. Bulletin of the Psychonomic Society, 1976, 8, 439-440.

(Received for publication January 5, 1978; revision accepted March 23, 1978.) 